\title{
Variation in ecosystem service values in response to land use changes in Zhifanggou watershed of Loess plateau: a comparative study
}

\author{
Jin $\mathrm{Si}^{1}$, Fuzhan Nasiri ${ }^{*}$, Peng Han ${ }^{2}$ and Tianhong $\mathrm{Li}^{2}$
}

\begin{abstract}
Background: Anthropological activities could lead to various land use changes. This subsequently exerts impacts on the Ecological status as the land is the carrier of Ecosystems and their services. Ecosystem Services Values (ESVs) are monetary assessment of ecosystems services. The choice of ecosystem services valuation methods highly depends on the type and conditions of the ecological environment.

Results: In this paper, Zhifangou watershed, a watershed with fragile environments in Loess Plateau, is analyzed in terms of the historical changes of land uses and their impact on Ecosystem Services Values (ESVs). The analysis presents that the watershed had seen a large cover of forest (689.8 hectare) and grassland (97.08 hectare) until 1938, which were substituted with a cropland of 663.56 hectare in the following years, and then a gradual recovery of natural land from 1978. During these years, the human activities have ranged from little disruption, to excessive cultivation, and finally to an integrated management of the watershed. The ESVs were highest at $\$ 121.77 \times 10^{4}$ in 1938 , lowest at $\$ 43.75 \times 10^{4}$ in 1958 , and then rebounded to $\$ 113.44 \times 10^{4}$ in 1999 .
\end{abstract}

Conclusions: The analysis reveals that the values of soil formation and retention, biodiversity protection, and climate regulation have been associated with the largest share of the total ESVs. Among them, soil formation and retention was recognized as the most impacted service by land use changes.

Keywords: Land use change; Ecosystem services; Valuation; Anthropological activities; Zhifanggou watershed

\section{Background}

The unprecedented population growth and urbanization over the past century has changed the face of the planet as a result of many land use changes. On the other hand, the land supplies mass and energy, which are the main drivers of economic development (Darwin et al. 1996) as well as various Ecosystem Services (ES). The latter are defined as the conditions and processes through which natural ecosystems and the species that comprise them, sustain and fulfill human well-being (Daily 1997). Some examples of such services provided by land cover are biodiversity, water filtration, retention of soil, and air purification, just to name a few (Nasiri and Huang 2007). As such, there exists a close correlation between land uses and the state of ecological environment (Styers et al.

\footnotetext{
*Correspondence: f.nasiri@ucl.ac.uk

'Bartlett School of Graduate Studies, University College London (UCL), London WC1H-ONN, UK

Full list of author information is available at the end of the article
}

2010). An inappropriate land allocation and use may lead to significant degradation of local and regional ecological services (Collin and Melloul 2001).

Ecosystem Services Values (ESVs) are monetary assessment of ES. Costanza et al. (1997) were first to propose a list of ecosystem valuation coefficients, estimating monetary values of 17 ecosystem services generated by 16 different biomes. Although the study has faced criticisms about double counting and/or underestimating or overestimating the listed values (Fu et al. 2011), it paved the path to the science of ES valuation. Turner et al. (1998) have proposed a refined set of coefficients. On that basis, Xie et al. (2003) developed a similar set of coefficients for valuation of ecosystem services in China by increasing the weight of ecosystem services related to agriculture and decreasing that of wetlands.

As the choice of ecosystem services valuation methods highly depends on the type and conditions of the ecological environment, most of the ESV methods suggested 
in the literature are case-specific. Kreuter et al. (2001) estimated ESVs for urban sprawl in the San Antonia area in Texas. Martínez et al. (2009) assessed the impacts of land use changes on the ES provision in tropical montage cloud forests. Li et al. (2010) investigated ES changes in response to land use changes caused mainly by climatic changes on the Zoige Plateau of Tibetan Plateau in China. Zhang et al. (2011) conducted a comparative study of ESVs based on land use changes in $\mathrm{HaDaQi}$ industrial corridor, in Heilongjiang Province of China.

Building on previous research by Xie et al. (2003) and Zhang et al. (2011) on the ESVs, in this paper we propose an ESV analysis of Zhifanggou watershed on the basis of historical data on land use changes. We have based our calculations on Xie et al. (2003) and Zhang et al. (2011) studies as they adjusted the ESV coefficients such that to be specific to China's ecosystems. The ESVs analysis of this area is of particular importance as it historically witnessed a period of destruction followed by a recovery as a result of employing an integrated watershed management framework. We analyze the changes in land-use and the associated ESVs, demonstrating the relationships between ecosystem changes and anthropological activities. The results may also provide insights about the impact of integrated watershed management programs, emphasizing the importance of ecosystem services conservation.

\section{Study area}

Zhifanggou watershed $\left(109^{\circ} 13^{\prime} 46^{\prime \prime} \sim 109^{\circ} 13^{\prime} 45^{\prime \prime} \mathrm{E}, 36^{\circ} 42^{\prime}\right.$ $42^{\prime \prime} \sim 36^{\circ} 46^{\prime} 28^{\prime \prime} \mathrm{N}$ ) is located in An'sai county of Shaanxi province in China. It is part of a hilly and gully region of Loess Plateau (Zhang et al. 2008). The size of the area, as shown in Figure 1, is estimated as $8.39 \mathrm{~km}^{2}$. The region is mainly affected by a semi-arid climate with an average annual rainfall of $541.2 \mathrm{~mm}$. Rainfall mainly occurs from July to September and heavy storm often leads to serious soil erosion in rainy seasons (Jiang and Zheng 2004).

Prior to 1938, the ecosystem of Zhifanggou watershed was seldom disturbed by human activities. However, from the 1938 to 1960 s local vegetation was destroyed heavily and soil erosion was intensified quickly due to population expansion and cultivation of large areas of slope land. Consequently, this was led to a fast deterioration of ecological environment (Wen et al. 2006). From 1973, an integrative watershed management program was started. This program was initiated to plan and manage mountains, rivers, fields and forests in the watershed under a unified framework. The main objectives were to control the soil erosion on different slopes, to aim for the recovery of the grassland, to protect the forest areas, and to promote the use of improved seeds and water-saving measures in farming. Zhifanggou watershed was selected as an experimental site for key research and development programs on integrative management of Loess Plateau ( $\mathrm{Li}$ 1995). After 20 years of integrative watershed management, the area of the watershed that is free from soil erosion is up to $12.21 \mathrm{~km}^{2}$, which is $81.4 \%$ of the whole area. As a result, the ecosystem of the watershed was gradually recovered to its previous natural state, benefiting from returning forest and grassland areas (Han et al. 2009).

The historical land use datasets of Zhifanggou watershed is divided through five milestone years of 1938, 1958, 1978, 1987 and 1999, indicating and capturing the ecological changes. The datasets used in this study were provided by the Key Laboratory for Water and Sediment

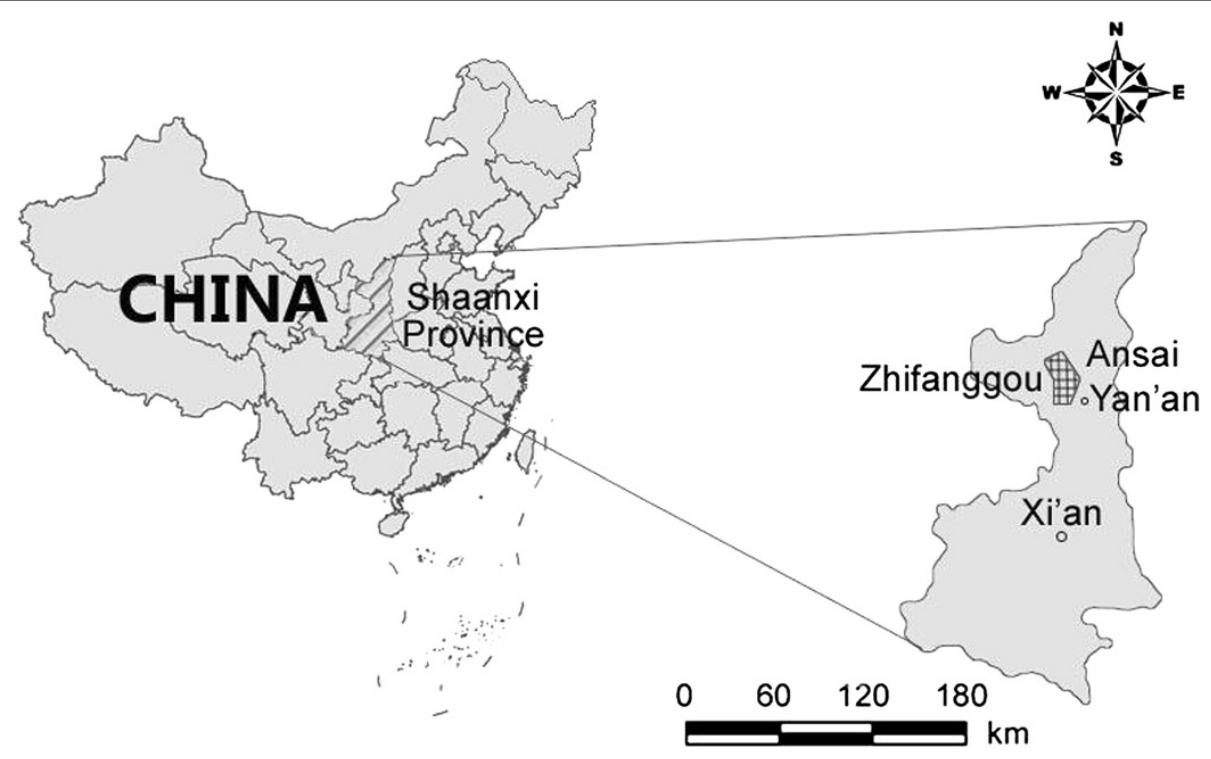

Figure 1 Location of Zhifanggou watershed. 
Sciences in Peking University in China. Data from 1958, 1978 and 1987 were acquired by aerial photograph interpretation aided by ground survey and existing land use maps. Data for 1999 were obtained through monitoring, while those of 1938 were based on records of interview and surveys.

We have reclassified the above datasets into seven categories of cropland, woodland, orchard land, grassland, water body, build up and barren lands (see Table 1). Data for woodland and orchard were combined as forest category. Land use maps of (1:5000) were calibrated and coded in ARCMAP 9.2 (ESRI 2013) for the subsequent spatial analysis and ecosystem services valuations.

\section{Methods}

Xie et al. (2003) extracted the coefficients of ecosystem services per hectare of terrestrial ecosystems in China. Adopting this model, we had to make the following minor adjustments to have it customized for Zhifanggou watershed as presented in Table 2:

(1) Due to the resolution of land use datasets, classifying the land types of wetland and water is of difficulty. In this sense, this two land types are considered as one type in this study, assigning with the mean coefficients of wetland and water. This way of dealing with multiple categories of water bodies has been advocated by Zhang et al. (2011).

(2) As 1990s data is regarded as a baseline for analysis in China's statistics, the average market price of agricultural produce per hectare was calculated using the 1990s data for major crops, including rice, wheat, corns and soybeans according to National Bureau of Statistic of China (NBSC 1996-1999).

The value of food production services of agricultural produce per hectare was computed, according to Xie et al. (2003), as one-seventh of the market price of agricultural produce. The estimated monetary value of

Table 1 Land use categories in Zhifanggou watershed

\begin{tabular}{|c|c|c|}
\hline Categories & & Definition \\
\hline \multirow[t]{2}{*}{ Cropland } & & $\begin{array}{l}\text { Paddy field, glebe field, irrigable land and } \\
\text { vegetable field }\end{array}$ \\
\hline & Orchard & $\begin{array}{l}\text { Orchard occupied by fruit, tea, mulberry and } \\
\text { rubber trees }\end{array}$ \\
\hline Forest & Woodland & $\begin{array}{l}\text { Arbor, bamboo, bush forest and protection } \\
\text { forest along the roads, railways and costal lines }\end{array}$ \\
\hline Grassland & & Natural grassland and man-made grassland \\
\hline Water body & & Wetlands, rivers, reservoirs fishery and lakes \\
\hline Buildup & & $\begin{array}{l}\text { Lands used for industrial, commercial, } \\
\text { residential, transportation ends }\end{array}$ \\
\hline Barren land & & Lands unused or difficult for any use \\
\hline
\end{tabular}

agricultural produce per hectare was estimated as $\$ 528.08$ (i.e. an equivalent of RMB Yuan 2525.92 according to the average exchange rate at the end of 1990s). Consequently, the value of the food production service provided by agricultural lands per hectare was estimated as $\$ 75.44$ (i.e. an equivalent of RMB Yuan 528.08). Finally, the value coefficients of ecosystem services were calculated by multiplying the food production values by their service to production ratios (see Table 3), as follows:

$$
V C_{k f}=R_{k f} \times V_{F}
$$

where,

$V C_{k f}$ : The ecosystem service value for ecosystem function $f$ in land use type $k$ ( $\$$ per hectare per year).

$R_{k f}$ : Ratio of ecosystem service to food production values for function $\mathrm{f}$ in land use type $\mathrm{k}$.

$V_{F}$ : Food production values of agriculture land per area per year, which is $\$ 75.44$ per hectare for 1990 base year.

Having the ecosystem service value of one unit area for each category of land use extracted, the service value for each category of land use and the service value of each function are obtained from Equations. (2) and (3):

$$
\begin{aligned}
& E S V_{k}=\sum_{f} A_{k} \times V C_{k f} \\
& E S V_{f}=\sum_{k} A_{k} \times V C_{k f} \\
& E S V=\sum_{k} \sum_{f} A_{k} \times V C_{k f}
\end{aligned}
$$

where

$E S V_{k}$ : Ecosystem service value of land use category " $k$ ". $E S V_{f}$ : Value of ecosystem service function type " $f$ ".

ESV : Total ecosystem service value of the watershed $A_{k}$ : Area (hectare) of land use category " $k$ ".

Since the biomes we used as proxies for land use categories were not perfect matches, and as a result of the uncertainties about the correspondence of proxies for land use types and the accuracy of Xie's value coefficients embedded in the estimation, we have conducted a sensitivity analysis to determine the impact of variations in the value of coefficients on ESVs estimations. For each ESV analysis, we then calculate a coefficient of sensitivity (CS) using the following formula that resembles the standard concept of elasticity in economics (Kreuter et al. 2001): 


\begin{tabular}{|c|c|c|c|c|c|}
\hline $\begin{array}{l}\text { Ecosystem } \\
\text { service }\end{array}$ & Forest & Grassland & Cropland & $\begin{array}{l}\text { Water } \\
\text { body }\end{array}$ & $\begin{array}{l}\text { Barren } \\
\text { lands }\end{array}$ \\
\hline Gas regulation & 3.5 & 0.8 & 0.5 & 0.9 & 0 \\
\hline Climate regulation & 2.7 & 0.9 & 0.89 & 8.78 & 0 \\
\hline Water supply & 3.2 & 0.8 & 0.6 & 17.94 & 0.03 \\
\hline $\begin{array}{l}\text { Soil formation and } \\
\text { retention }\end{array}$ & 3.9 & 1.95 & 1.46 & 0.86 & 0.02 \\
\hline Waste treatment & 1.31 & 1.31 & 1.64 & 18.18 & 0.01 \\
\hline $\begin{array}{l}\text { Biodiversity } \\
\text { protection }\end{array}$ & 3.26 & 1.09 & 0.71 & 2.495 & 0.34 \\
\hline Food & 0.1 & 0.3 & 1 & 0.2 & 0.01 \\
\hline Raw material & 2.6 & 0.05 & 0.1 & 0.04 & 0 \\
\hline $\begin{array}{l}\text { Recreation and } \\
\text { culture }\end{array}$ & 1.28 & 0.04 & 0.01 & 4.945 & 0.01 \\
\hline
\end{tabular}

$$
C S_{k f}=\frac{\left(E S V^{(j)}-E S V^{(i)}\right) / E S V^{(i)}}{\left(V C_{k f}^{(j)}-V C_{k f}^{(i)}\right) / V C_{k f}^{(i)}}
$$

where $i$ and $j$ represent the initial and adjusted values, respectively. If $C S_{k f}>1$, then the estimated ecosystem value is elastic (i.e. highly sensitive) with respect to changes in value of $V C_{k f}$ coefficient, but if $C S_{k f}<1$, then the estimated ecosystem value is inelastic (i.e. not sensitive) with respect to changes in value of $V C_{k f}$ coefficient.

Table 3 Ecosystem service value coefficients for each land use category obtained from equation (1) (\$ per hectare per year ; ; revised from Xie et al. 2003)

\begin{tabular}{lccccc}
\hline $\begin{array}{l}\text { Ecosystem } \\
\text { service }\end{array}$ & Forest & Grassland & Cropland & $\begin{array}{c}\text { Water } \\
\text { body }\end{array}$ & $\begin{array}{c}\text { Barren } \\
\text { lands }\end{array}$ \\
\hline Gas regulation & 264 & 60 & 38 & 68 & 0 \\
$\begin{array}{lccc}\text { Climate regulation } \\
\text { Water supply }\end{array}$ & 244 & 68 & 67 & 662 & 0 \\
$\begin{array}{l}\text { Soil formation and } \\
\text { retention }\end{array}$ & 294 & 147 & 110 & 65 & 2 \\
Waste treatment & 99 & 99 & 124 & 1372 & 1 \\
$\begin{array}{l}\text { Biodiversity } \\
\text { protection }\end{array}$ & 246 & 82 & 54 & 188 & 26 \\
Food & 8 & 23 & 75 & 15 & 1 \\
Raw material & 196 & 4 & 8 & 3 & 0 \\
Recreation and & 97 & 3 & 1 & 373 & 1 \\
culture & & & 546 & 4099 & 32 \\
Total & 1648 & 546 & 521 & & \\
\hline
\end{tabular}

${ }^{*}$ The coefficients are adjusted to $1990 \$$ according to the exchange rate between RMB Yuan and \$.

\section{Results}

Changes of land use

The data on historical land use changes (as shown in Figure 2) are summarized in Table 4. In 1938, the watershed was comprised of a large area of forest (689.8 hectare), an area of grassland (97.08 hectare) and a small area of cropland (52.19 hectare). However, this condition was interrupted in 1958, with increased farming activities, causing the area of forest to drop to 1.09 hectare. The cropland and grassland areas have increased to 663.56 hectare and 136.69 hectare, respectively. Meanwhile, the area of build up, water body and unused land had also increased to 1.51, 3.32 and 32.89 hectare, respectively. Then in 1978, as a result of introducing an integrated watershed management program, the area of forest and grassland increased to 16.98 hectare and 615.32 hectare, respectively, and with decline of cropland area to 170 hectare. Until 1987, the area of forest soared to 562.11 hectare due to further transformations. Finally in 1999, the watershed was covered with a forest area of 618.1 hectare, returning to its status in 1938. Since then, the watershed consists of 93.15 hectare of cropland, 121.85 hectare of grassland and 5.97 hectare of build up (without any land use categories of water body and unused land).

A comparative analysis of the land uses over the years indicates that each land use type went through dramatic changes in four periods of 1938-1958, 1958-1978, 19781987 and 1987-1999. The area of forest decreased by 4.99\% annually from 1938 to 1958 , and increased by $72.89 \%, 356.71 \%$ and $0.83 \%$ annually in the next three periods. Contrastively, the area of cropland increased by $58.57 \%$ in the first period, and constantly decreased by $74.38 \%, 14.59 \%$ and $2.99 \%$ annually in the later periods. In case of grassland, the most significant decrease took place between 1978 and 1987 (84.27\% annually), when the forest area became mature again. As for build up land uses, there has been a constant increase in all periods, with a dramatic increase of $11.81 \%$ annually in the last period. This was subject to a fast growth of urbanization during this period. The water bodies and barren lands could only be seen between 1958 and 1987 .

\section{Changes of ESVs}

ESVs for each land category and the overall ESVs were obtained, according to Equations 2 and 4, for each period as reported in Table 5. The total ESVs for Zhifanggou watershed was estimated at $\$ 121.77 \times 10^{4}$ in $1938, \$ 43.75 \times 10^{4}$ in $1958, \$ 46.73 \times 10^{4}$ in $1978, \$ 107.01 \times 10^{4}$ in 1987 and $\$ 113.44 \times 10^{4}$ in 1999 . From 1938 to 1958 , the total ESVs dropped by $64.07 \%$, or $3.20 \%$ annually. From 1958 to 1978 , the total ESVs increased by $6.81 \%$, or $0.34 \%$ annually. And from 1978 to 1987, the total ESVs rose largely by $129 \%$, or $14.33 \%$ annually. Finally from 1987 to 1999, the total ESVs retained a slow increase by $6.01 \%$ (or $0.5 \%$ annually). 


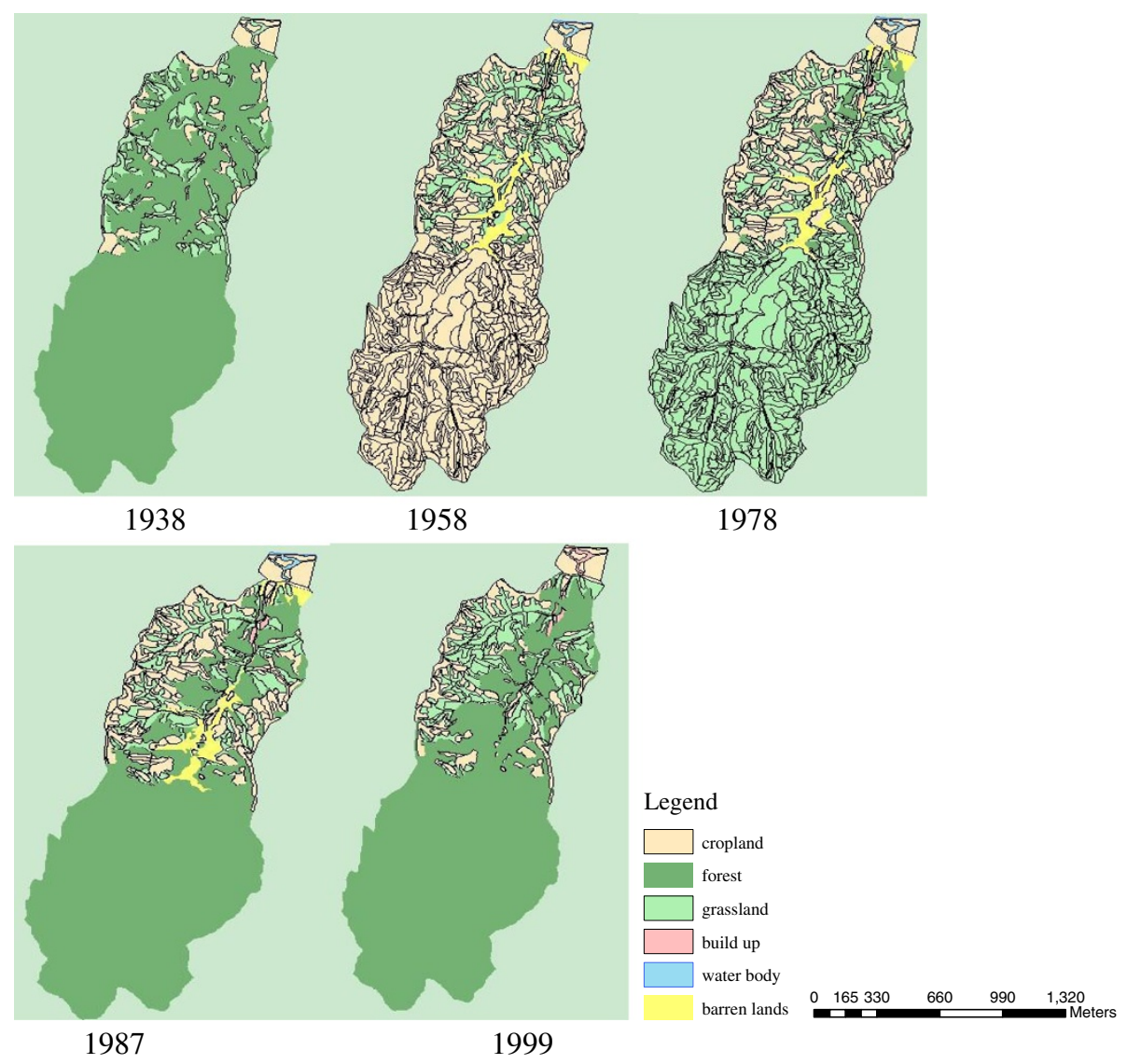

Figure 2 Land use maps derived from 1938, 1958, 1978, 1987 and 1999 data.

From Table 5, among various types of land, forest produced the largest ESVs due to its highest ecosystem services coefficients and large areas. Among other types of land use, the grassland provided the watershed with higher ESVs. Contrastively, the cropland supplied the lowest ESVs, except the period beginning in 1958 when it was associated with a large area. Although, the water body could provide high ESVs in theory, but this was insignificant in Zhifanggou watershed with small water body areas. The sum of ecosystem service values provided by forest, grassland and cropland accounted for over $90 \%$ of the total value, indicating their main role in ecosystem service provision in Zhifanggou watershed.

According to Equation 3, the ecosystem service values provided by individual ecosystem functions were also estimated (see Table 6). The ranking for all the functions were based on its contributions to the total ESVS. The impact of each ecosystem function on total value of the ecosystem services was represented by an upward arrow “ $\uparrow$ " for increasing (or reinforcing) impacts, downward arrow " $\downarrow$ " for decreasing (or balancing) impacts, and a dash "-" for no or negligible impacts. The overall ranking for the studied periods were estimated based on the average impact of individual ESVs on total ESVs. These impacts, from high to low, are: soil formation and retention, biodiversity protection, climate regulation, gas regulation, water supply, climate regulation, waste treatment, raw material, recreation and culture, and food. The share of soil formation and retention service was the highest (about 20\%), followed by biodiversity protection, gas regulation and climate regulation (each around $14 \%$ ), all of which are major ecosystem functions mainly derived from the forest areas.

\section{Discussion}

Using Equation 5, we conduct a sensitivity analysis with an extreme $50 \%$ adjustment in the value of the ecosystem services coefficients. The results, as reported in Table 7 , indicate that CS values in all studied periods were below 1 , which means that the estimated overall ecosystem value (ESV) was considered to be inelastic (low sensitive) to the change in coefficient values. We can conclude that the ESV calculations are consistent and reliable with a minimum impact from variations in estimation of $\mathrm{VC}$ values caused by occasional data inaccuracies. The highest CS scores belong to forest in 1938, 1987 and 1999, cropland in 1958, and grassland in 1978 (i.e. the land uses with large areas and big value coefficients). 
Table 4 Land-use changes from 1938 to 1999

\begin{tabular}{|c|c|c|c|c|c|c|}
\hline & \multirow[t]{2}{*}{ Land Uses } & \multicolumn{5}{|c|}{ Years } \\
\hline & & 1938 & 1958 & 1978 & 1987 & 1999 \\
\hline \multirow[t]{3}{*}{ Forest } & Land-use (hectare) & 689.8 & 1.09 & 16.98 & 562.11 & 618.1 \\
\hline & $\%$ of Change & - & -99.84 & 1457.80 & 3210.42 & 9.96 \\
\hline & Average Annual \% of Change & - & -4.99 & 72.89 & 356.71 & 0.83 \\
\hline \multirow[t]{3}{*}{ Grassland } & Land-use (hectare) & 97.08 & 136.69 & 615.32 & 96.79 & 121.85 \\
\hline & $\%$ of Change & - & 40.80 & 350.16 & -84.27 & 25.89 \\
\hline & Average Annual \% of Change & - & 2.04 & 17.51 & -9.36 & 2.16 \\
\hline \multirow[t]{3}{*}{ Cropland } & Land-use (hectare) & 52.19 & 663.56 & 170 & 145.19 & 93.15 \\
\hline & $\%$ of Change & - & 1171.43 & -74.38 & -14.59 & -35.84 \\
\hline & Average Annual \% of Change & - & 58.57 & -3.72 & -1.62 & -2.99 \\
\hline \multirow[t]{3}{*}{ Build up } & Land-use (hectare) & 0.00 & 1.51 & 2.04 & 2.47 & 5.97 \\
\hline & $\%$ of Change & - & - & 35.10 & 21.08 & 141.70 \\
\hline & Average Annual \% of Change & - & - & 1.75 & 2.34 & 11.81 \\
\hline \multirow[t]{3}{*}{ Water body } & Land-use (hectare) & 0.00 & 3.32 & 3.32 & 3.32 & 0.00 \\
\hline & $\%$ of Change & - & - & 0.00 & 0.00 & -100.00 \\
\hline & Average Annual \% of Change & - & - & 0.00 & 0.00 & -8.33 \\
\hline \multirow[t]{3}{*}{ Unused land } & Land-use (hectare) & 0.00 & 32.89 & 31.39 & 29.18 & 0.00 \\
\hline & $\%$ of Change & - & - & -4.56 & -7.04 & -100.00 \\
\hline & Average Annual \% of Change & - & - & -0.23 & -0.78 & -8.33 \\
\hline
\end{tabular}

Table 5 Ecosystem service values of Zhifanggou watershed from 1938 to 1999

\begin{tabular}{|c|c|c|c|c|c|c|}
\hline & \multirow{2}{*}{ ESVs } & \multicolumn{5}{|c|}{ Years } \\
\hline & & 1938 & 1958 & 1978 & 1987 & 1999 \\
\hline & ESV $\left(10^{4} \$ /\right.$ year $)$ & 113.75 & 0.18 & 2.8 & 92.69 & 101.92 \\
\hline \multirow[t]{3}{*}{ Forest } & $\%$ of Change & - & -99.84 & 1455.56 & 3210.36 & 9.96 \\
\hline & Average Annual \% of Change & - & -4.99 & 72.78 & 356.71 & 0.83 \\
\hline & ESV $\left(10^{4} \$ /\right.$ year $)$ & 5.3 & 7.46 & 33.6 & 5.28 & 6.65 \\
\hline \multirow[t]{3}{*}{ Grassland } & $\%$ of Change & - & 40.75 & 350.4 & -84.29 & 25.95 \\
\hline & Average Annual \% of Change & - & 2.04 & 17.52 & -9.37 & 2.16 \\
\hline & ESV $\left(10^{4} \$ /\right.$ year $)$ & 2.72 & 34.64 & 8.87 & 7.58 & 4.86 \\
\hline \multirow[t]{3}{*}{ Cropland } & $\%$ of Change & - & 1173.53 & -74.39 & -14.54 & -35.88 \\
\hline & Average Annual \% of Change & - & 58.68 & -3.72 & -1.62 & -2.99 \\
\hline & ESV $\left(10^{4} \$ /\right.$ year $)$ & 0 & 1.36 & 1.36 & 1.36 & 0.00 \\
\hline \multirow[t]{3}{*}{ Water body } & $\%$ of Change & - & - & 0.00 & 0.00 & -100.00 \\
\hline & Average Annual \% of Change & - & - & 0.00 & 0.00 & -8.33 \\
\hline & ESV $\left(10^{4} \$ /\right.$ year $)$ & 0 & 0.11 & 0.10 & 0.10 & 0.00 \\
\hline \multirow[t]{3}{*}{ Barren land } & $\%$ of Change & - & - & -9.09 & 0.00 & -100.00 \\
\hline & Average Annual \% of Change & - & - & -0.45 & 0.00 & -8.33 \\
\hline & ESV $\left(10^{4} \$ /\right.$ year $)$ & 121.77 & 43.75 & 46.73 & 107.01 & 113.44 \\
\hline \multirow[t]{2}{*}{ Total } & $\%$ of Change & - & -64.07 & 6.81 & 129.00 & 6.01 \\
\hline & Average Annual \% of Change & - & -3.20 & 0.34 & 14.33 & 0.50 \\
\hline
\end{tabular}


Table 6 ESVs associated with ecosystem service functions $\left(10^{4} \$\right.$, with 1990 as the base year)

\begin{tabular}{|c|c|c|c|c|c|c|c|c|c|c|c|}
\hline \multirow[t]{3}{*}{ Ecosystem services } & \multicolumn{10}{|c|}{ Years } & \multirow[t]{3}{*}{ Rank } \\
\hline & \multicolumn{2}{|c|}{1938} & \multicolumn{2}{|r|}{1958} & \multicolumn{2}{|r|}{1978} & \multicolumn{2}{|c|}{1987} & \multicolumn{2}{|c|}{1999} & \\
\hline & ESVs & $\%$ Change & ESVs & $\%$ Change & ESVs & $\%$ Change & ESVs & $\%$ Change & ESVs & $\%$ Change & \\
\hline Gas regulation & 18.99 & 15.60 & 3.39 & 7.76 & 4.81 & 10.29 & 15.99 & 14.95 & 17.40 & 15.34 & $\downarrow$ \\
\hline Climate regulation & 15.08 & 12.39 & 5.62 & 12.84 & 5.89 & 12.60 & 13.32 & 12.45 & 14.06 & 12.40 & $\uparrow$ \\
\hline Water supply & 17.44 & 14.32 & 4.29 & 9.80 & 5.32 & 11.39 & 15.24 & 14.24 & 16.05 & 14.15 & $\downarrow$ \\
\hline Soil formation and retention & 22.28 & 18.30 & 9.37 & 21.41 & 11.44 & 24.48 & 19.57 & 18.29 & 20.99 & 18.50 & $\uparrow$ \\
\hline Waste treatment & 8.44 & 6.93 & 10.05 & 22.97 & 8.83 & 18.89 & 8.78 & 8.21 & 8.48 & 7.48 & $\uparrow$ \\
\hline Biodiversity protection & 18.05 & 14.82 & 4.88 & 11.15 & 6.53 & 13.96 & 15.54 & 14.53 & 16.71 & 14.73 & $\downarrow$ \\
\hline Food & 1.17 & 0.96 & 5.30 & 12.11 & 2.71 & 5.80 & 1.77 & 1.65 & 1.47 & 1.30 & $\uparrow$ \\
\hline Raw material & 13.60 & 11.17 & 0.61 & 1.39 & 0.72 & 1.53 & 11.17 & 10.44 & 12.24 & 10.79 & $\downarrow$ \\
\hline Recreation and culture & 6.73 & 5.52 & 0.25 & 0.56 & 0.49 & 1.06 & 5.62 & 5.25 & 6.04 & 5.33 & $\downarrow$ \\
\hline Total & 121.77 & 100 & 43.75 & 100 & 46.73 & 100 & 107.01 & 100 & 113.44 & 100 & - \\
\hline
\end{tabular}

The historical changes in ecosystem services values of Zhifanggou watershed were triggered by several factors described as follows:

Population: There were only 94 local residents in Zhifanggou watershed in 1938. This number increased to 221 in 1958 as a result of advances in nationwide medical care and increase in farming activities. From 1970s, the policy of birth control began to implement, and the growth of local population was slowed to 476 people in 1990, with a balancing impact on build up land use.

Land Policy: Prior to 1978, there was no local ownership of the croplands. This was a major factor in low productivity of croplands as there was little motivation for locals to cultivate efficiently. In 1978, when the third Plenary Session of the Eleventh Central Committee in China took place, a directive for local management of croplands was proposed. This came into effect in 1985, triggering an increase in productivity of croplands and reducing the need to more land-uses of this type.

Technological Change: Technological developments in farming also contributed to improvements in croplands productivity. Before 1970s, farming was mainly carried out using low-tech methods, leading to unproductive practices and overexploitation and deterioration of soil. From 1970s, there were technological advances such as new cultivation approaches for intercropping, mulching technologies, and efficient pest control methods, all of which contributed to high productivity of croplands. Water and Soil Conservation: In Zhifanggou watershed, notorious conditions such as little vegetations, loose soil and heavy rain impose pressure on local environmental protection. From 1977, locals began to cultivate on slope lands, modifying them to terraces and paying higher attention to soil conservation. In addition, Zhifanggou watershed was chosen as a test zone for water and soil conservation projects in late 1980s, when the local government began to implement integrated water, land and economic development plans in the region, increasing the ecosystem services value of the watershed.

\section{Conclusions}

We have customized the ecosystem services valuation approach developed by Costanza et al. (1997) according to Xie et al. (2003) to account for specific characteristics of ecosystems in China. In addition, to address the overestimation or underestimation of service values in Xie et al. (2003) approach (as shown by Fu et al. (2011), we have revised some of the coefficient. A sensitivity analysis was also employed to test of the impact of variations in coefficients on estimation of ecosystem services values. The analysis revealed that the estimation of ecosystem service coefficients was robust despite the imposed fluctuations.

We have used the land use as a proxy measure of ecosystem services. It should be mentioned that the accuracy of satellites images could significantly influence the accuracy of the results, generating more detailed data, such as information on individual trees or hidden water bodies. Moreover, the biomes and land categories are not always matched. For example, the woodland and orchard uses were jointly considered as forest in this study.

In Zhifanggou watershed, with little human activities until 1938, the watershed was then covered with large areas of forest (689.8 hectare) and grassland (97.08 hectare). During 1938-1958, the growth of population mixed with cropland expansion led to a dramatic decline of forest and grassland at a rate of $2.04 \%$ each year. The subsequent decline of ecosystem services values was finally recognized by the local government, and an integrative watershed management program was introduced. With the support of government policies, the area of forest and grassland recovered at a rate of $168.58 \%$ per year 
Table 7 Sensitivity of ecosystem valuation coefficients

\begin{tabular}{|c|c|c|c|c|c|c|}
\hline \multirow[t]{2}{*}{ Land use } & \multirow[t]{2}{*}{ Ecosystem services } & \multicolumn{5}{|c|}{ Year } \\
\hline & & 1938 & 1958 & 1978 & 1987 & 1999 \\
\hline \multirow[t]{9}{*}{ Forest } & Gas regulation & 0.15 & 0.00 & 0.01 & 0.14 & 0.14 \\
\hline & Climate regulation & 0.12 & 0.00 & 0.01 & 0.11 & 0.11 \\
\hline & Water supply & 0.14 & 0.00 & 0.01 & 0.13 & 0.13 \\
\hline & Soil formation and retention & 0.17 & 0.00 & 0.01 & 0.15 & 0.16 \\
\hline & Waste treatment & 0.06 & 0.00 & 0.00 & 0.05 & 0.05 \\
\hline & Biodiversity protection & 0.14 & 0.00 & 0.01 & 0.13 & 0.13 \\
\hline & Food & 0.00 & 0.00 & 0.00 & 0.00 & 0.00 \\
\hline & Raw material & 0.11 & 0.00 & 0.01 & 0.10 & 0.11 \\
\hline & Recreation and culture & 0.05 & 0.00 & 0.00 & 0.05 & 0.05 \\
\hline \multirow[t]{9}{*}{ Grassland } & Gas regulation & 0.00 & 0.02 & 0.08 & 0.01 & 0.01 \\
\hline & Climate regulation & 0.01 & 0.02 & 0.09 & 0.01 & 0.01 \\
\hline & Water supply & 0.00 & 0.02 & 0.08 & 0.01 & 0.01 \\
\hline & Soil formation and retention & 0.01 & 0.05 & 0.19 & 0.01 & 0.02 \\
\hline & Waste treatment & 0.01 & 0.03 & 0.13 & 0.01 & 0.01 \\
\hline & Biodiversity protection & 0.01 & 0.03 & 0.11 & 0.01 & 0.01 \\
\hline & Food & 0.00 & 0.01 & 0.03 & 0.00 & 0.00 \\
\hline & Raw material & 0.00 & 0.00 & 0.01 & 0.00 & 0.00 \\
\hline & Recreation and culture & 0.00 & 0.00 & 0.00 & 0.00 & 0.00 \\
\hline \multirow[t]{9}{*}{ Cropland } & Gas regulation & 0.00 & 0.06 & 0.01 & 0.01 & 0.00 \\
\hline & Climate regulation & 0.00 & 0.10 & 0.02 & 0.01 & 0.01 \\
\hline & Water supply & 0.00 & 0.07 & 0.02 & 0.01 & 0.00 \\
\hline & Soil formation and retention & 0.00 & 0.17 & 0.04 & 0.01 & 0.01 \\
\hline & Waste treatment & 0.01 & 0.19 & 0.05 & 0.02 & 0.01 \\
\hline & Biodiversity protection & 0.00 & 0.08 & 0.02 & 0.01 & 0.00 \\
\hline & Food & 0.00 & 0.11 & 0.03 & 0.01 & 0.01 \\
\hline & Raw material & 0.00 & 0.01 & 0.00 & 0.00 & 0.00 \\
\hline & Recreation and culture & 0.00 & 0.00 & 0.00 & 0.00 & 0.00 \\
\hline \multirow[t]{9}{*}{ Water body } & Gas regulation & 0.00 & 0.00 & 0.00 & 0.00 & 0.00 \\
\hline & Climate regulation & 0.00 & 0.01 & 0.00 & 0.00 & 0.00 \\
\hline & Water supply & 0.00 & 0.01 & 0.01 & 0.00 & 0.00 \\
\hline & Soil formation and retention & 0.00 & 0.00 & 0.00 & 0.00 & 0.00 \\
\hline & Waste treatment & 0.00 & 0.01 & 0.01 & 0.00 & 0.00 \\
\hline & Biodiversity protection & 0.00 & 0.00 & 0.00 & 0.00 & 0.00 \\
\hline & Food & 0.00 & 0.00 & 0.00 & 0.00 & 0.00 \\
\hline & Raw material & 0.00 & 0.00 & 0.00 & 0.00 & 0.00 \\
\hline & Recreation and culture & 0.00 & 0.00 & 0.00 & 0.00 & 0.00 \\
\hline \multirow[t]{5}{*}{ Barren land } & Gas regulation & 0.00 & 0.00 & 0.00 & 0.00 & 0.00 \\
\hline & Climate regulation & 0.00 & 0.00 & 0.00 & 0.00 & 0.00 \\
\hline & Water supply & 0.00 & 0.00 & 0.00 & 0.00 & 0.00 \\
\hline & Soil formation and retention & 0.00 & 0.00 & 0.00 & 0.00 & 0.00 \\
\hline & Waste treatment & 0.00 & 0.00 & 0.00 & 0.00 & 0.00 \\
\hline
\end{tabular}


Table 7 Sensitivity of ecosystem valuation coefficients (Continued)

\begin{tabular}{cccccc} 
Biodiversity protection & 0.00 & 0.00 & 0.00 & 0.00 & 0.00 \\
Food & 0.00 & 0.00 & 0.00 & 0.00 & 0.00 \\
Raw material & 0.00 & 0.00 & 0.00 & 0.00 & 0.00 \\
Recreation and culture & 0.00 & 0.00 & 0.00 & 0.00 & 0.00 \\
\hline
\end{tabular}

from 1978 to 1999 . In 1999, the area of forest was fully recovered to its original state.

Land use changes in Zhifanggou watershed resulted in changes in ecosystem services. In 1938, the sum of ESVs was estimated at $\$ 121.77 \times 10^{4}$. It had dramatically decreased to $\$ 43.75 \times 10^{4}$ in 1958 . From 1958 to 1978 , the sum of ESVs increased marginally owing to the local government policies. From 1978, Zhifanggou watershed was chosen to serve as a test zone for the government's integrative watershed management program. This further increased the sum of ESVs to $\$ 107.01 \times 10^{4}$ in 1987 . As a result of such steady improvements the sum of ESVs for Zhifanggou watershed reached to $\$ 113.44 \times 10^{4}$ in 1999, nearly back to its peak in 1938. Reviewing specific ecosystem services, the values of soil formation and retention, biodiversity protection, gas regulation and climate regulation were forming the largest part of the total ESVs. Among these services, soil formation and retention was recognized as the most impacted service by land use changes, corresponding to the highest rate of change. This was due to the fact that the low productivity of land forced local residents to farm more intensively, which led to much severer soil erosion.

This study can be extended in several ways. First, the impact of crop yield differences in the study area over the years can be investigated. These differences might be due to natural causes or triggered by the use of improved farming technology. In addition, due to space limitations, we have only used a 50\% adjustment rate for our sensitivity analysis. It would be interesting to investigate the outcomes of various sensitivity analyses approaches with varied rates of adjustment. It should also be mentioned that the choice of ESV calculation methodology and the associated coefficients are casespecific. We have developed a calculation framework on the basis of Xie et al. (2003) coefficients for China's ecosystems. Comparing the outcomes of ESV calculations obtained for a case area using different bases for estimation of coefficients would certainly enhance our understanding of their applicability and limitations.

\section{Competing interests}

The authors declared that they have no competing interests.

\section{Authors' contributions}

The authors have co-developed the research agenda and analysis. JS and FN have drafted and revised the manuscript. All authors have read and approved the final manuscript.

\section{Acknowledgements}

This research was supported by the National Natural Science Foundation of China. The authors are very much thankful to two reviewers of this paper whose comments and suggestions were very helpful in improving the manuscript.

\section{Author details}

${ }^{1}$ Bartlett School of Graduate Studies, University College London (UCL), London WC1H-ONN, UK. ${ }^{2}$ The Key Laboratory of Water and Sediment Science, Department of Environmental Engineering, Peking University, Beijing 100871, China

Received: 23 August 2013 Accepted: 13 November 2013

Published: 13 January 2014

\section{References}

Collin ML, Melloul AJ (2001) Combined land-use and environmental factors for sustainable groundwater management. Urban Water 3:229-237

Costanza R, Arge RD, Groot RD, Farber S, Grasso M, Hannon B, Limburg K, Naeem S, Neill RVO, Paruelo J, Raskin RG, Sutton P, Belt MVD (1997) The value of the world's ecosystem services and natural capital. Nature 386:253-260

Daily GC (1997) Nature's Services: Societal Dependence on Natural Ecosystems. Island Press Washington D.C, USA

Darwin R, Tsigas M, Lewandrowski J, Raneses A (1996) Land use and cover in ecological economics. Ecol Econ 17:157-181

ESRI (2013) ARCGIS for Desktop, ESRI Itd. http://www.esri.com/software/arcgis/ arcgis-for-desktop (Last accessed on: August 10-2013)

Fu BJ, Wei YP, Willett IR, Lu YH, Liu GH (2011) Double counting in ecosystem services valuation: causes and countermeasures. Ecol Res 26:1-14

Han P, Si J, Wang YG (2009) Contrastive analysis of valuation methods of ecosystem services value: a case study of Zhifanggou watershed in a hilly and gully region of loess plateau. J Basic Sci Eng 17:102-111

Jiang ZS, Zheng FL (2004) Assessment on benefit of sediment reduction by comprehensive controls in the Zhifanggou Watershed. J Sediment Res 2:56-61

Kreuter UP, Harris HG, Matlock MD, Lacey RE (2001) Change in ecosystem service values in the San Antonio area, Texas. Ecol Econ 39:333-346

Li BC (1995) The remote sensing monitoring of soil erosion and integrated management in watersheds. Press of Science, China

Li JC, Wang WL, Hu GY, Wei ZH (2010) Changes in ecosystem service values in Zoige Plateau, China. Agric Ecosyst Environ 139:766-770

Martínez ML, Perez-Maqueo O, Vazquez G, Castillo-Campos G, García-Franco J, Mehltreter K, Equihua M, Landgrave R (2009) Effects of land use change on biodiversity and ecosystem services in tropical montane cloud forests of Mexico. For Ecol Manage 258:1856-1863

Nasiri F, Huang GH (2007) Ecological viability assessment: A fuzzy multipleattribute analysis with respect to three classes of ordering techniques. Ecol Inform 2:128-137

NBSC (1996-1999) National Bureau of Statistic of China (1996-1999 yearly data sets). http://www.stats.gov.cn/english/statisticaldata/yearlydata (Last accessed on: August 10-2013)

Styers DM, Chappelka AH, Marzen LJ, Somers GL (2010) Developing a land-cover classification to select indicators of forest ecosystem health in a rapidly urbanizing landscape. Landsc Urban Plan 94:158-165

Turner RK, Adger N, Brouwer R (1998) Ecosystem services value, research needs and policy relevance: a commentary. Ecol Econ 25:61-65

Wen ZM, Jiao F, He X, Yang Q, Liu B (2006) Increase of land productivity and its implication for eco-environment improvement: a case study in Zhifanggou catchment in loess hilly areas. Trans Chin Soc Agric Eng 22:91-95 
Xie GD, Lu C, Leng Y, Zheng D, Li S (2003) Ecological assets valuation of the Tibetan Plateau. J Nat Resour 18:189-196

Zhang CX, Xie GD, Yang QK (2008) Assessment of human activities on soil conservation value in hilly and gully region of Loess Plateau. J Nat Resour 23:1035-1042

Zhang S, Wu C, Liu H, Na X (2011) Impact of urbanization on natural ecosystem service values: a comparative study. Environ Monit Assess 179:575-588

doi:10.1186/2193-2697-3-2

Cite this article as: Si et al.: Variation in ecosystem service values in response to land use changes in Zhifanggou watershed of Loess plateau: a comparative study. Environmental Systems Research 2014 3:2.

Submit your manuscript to a SpringerOpen ${ }^{\circ}$ journal and benefit from:

- Convenient online submission

- Rigorous peer review

- Immediate publication on acceptance

- Open access: articles freely available online

- High visibility within the field

- Retaining the copyright to your article

Submit your next manuscript at springeropen.com 